\title{
Syntheses, Structures, and Properties of Copper(II), Cobalt(II), and Cadmium(II) Complexes with Flexible Multicarboxylate Ligand
}

\author{
Xianrui Xu, ${ }^{[a, b]}$ Xiaobo Pan, ${ }^{*[a]}$ Sifu Tang, ${ }^{[a]}$ Xiaoxia Lv, ${ }^{[a, b]}$ Liangjun Li, ${ }^{[a, b]}$ and \\ Xuebo Zhao*[a]
}

Keywords: Crystal structure; Flexible ligand; Hydrothermal synthesis; Coordination polymers; Photoluminescence

Abstract. Three new coordination polymers, namely, $\left[\mathrm{CuL}_{0.5}\right](\mathbf{1})$, $\left[\mathrm{Co}\left(\mathrm{H}_{2} \mathrm{~L}\right)\left(\mathrm{H}_{2} \mathrm{O}\right)_{2}\right]\left[\mathrm{H}_{2} \mathrm{O}\right]$ (2), and $\left[(\mathrm{CdCl})_{0.5} \mathrm{Cd}_{0.25}\left(\mathrm{H}_{2} \mathrm{~L}\right)_{0.5}\right]$ (3) were synthesized under hydrothermal conditions from the corresponding $\mathrm{Cu}^{\mathrm{II}}, \mathrm{Co}^{\mathrm{II}}$, and $\mathrm{Cd}^{\mathrm{II}}$ salts with a multidentate ligand of $2,2^{\prime}, 2^{\prime \prime}, 2^{\prime \prime \prime}$ [2,3,5,6-tetramethyl-1,4-phenylenebis(methylenenitrilo)]tetraacetic acid $\left(\mathrm{H}_{4} \mathrm{~L}\right)$. The complexes were characterized by single-crystal X-ray diffraction, IR, thermogravimetric, and elemental analyses. Complex 1 crystallizes in the orthorhombic space group Pbca and has a threedimensional architecture with infinite two-dimensional networks linked together by weak $\mathrm{Cu}-\mathrm{O}$ interactions. Complex $\mathbf{2}$ crystallizes in the monoclinic space group $P 2(1)$ and displays a 2D network. Complex 3 crystallizes in the tetragonal space group $P 4(2) / n c m$ and exhibits an infinite 3D architecture that has unusual $\left[\mathrm{Cd}_{2}\left(\mathrm{CO}_{2}\right)_{4} \mathrm{Cl}_{2}\right]$ dinuclear paddle-wheel units and $\left[\mathrm{Cd}\left(\mathrm{CO}_{2}\right)_{4}\right]$ dodecahedron units. The results showed that the coordination arrangement of central metal atoms and the conformation and coordination mode of organic ligands play an important role in determining the structure of the complexes. The luminescence property of complex $\mathbf{3}$ was studied in the solid state at room temperature.

\section{Introduction}

Recent years have witnessed intense research in the rational design and synthesis of metal-organic coordination polymers, not only due to their interesting topologies but also because of their potential applications as functional materials in fields such as molecular magnetism, catalysis, luminescence, gas adsorption, etc. ${ }^{[1,2]}$ Metal-organic complexes exhibit diversified structures because the coordination arrangement of the selected metal ions, the adopted bridging modes of the organic ligands, counterions, templates, and the reaction conditions such as temperature, solvent, $\mathrm{pH}$ value, and the ratio between metal salts and ligands exert crucial influences on the construction of the final results. ${ }^{[3]}$ However, it is still a great challenge to predict the exact structures and composition of the assembled products, and further studies are required to understand the assembly process of metal salts and organic linkers.

So far, most of research efforts have been devoted to rigid polycarboxylate ligands, ${ }^{[4,5]}$ such as 1,4-benzenedicarboxylic acid, 1,3,5-benzenetricarboxylic acid ( $\left.\mathrm{H}_{3} \mathrm{BTC}\right)$, 1,3,5-benzenetriacetic acid ( $\left.\mathrm{H}_{3} \mathrm{BTA}\right)$, 1,2,4,5-benzenetetracarboxylic acid

\footnotetext{
* Dr. X. Pan

E-Mail: panxb05@hotmail.com

* Prof. Dr. X. Zhao

Fax: +86-532-80662729

E-Mail: zhaoxb@qibebt.ac.cn

[a] Qingdao Institute of Bioenergy and Bioprocess Technology Chinese Academy of Sciences

266101, Qingdao, P. R. China

[b] University of Chinese Academy of Sciences 100049, Beijing, P. R. China

Supporting information for this article is available on the WWW under http://dx.doi.org/10.1002/zaac.201300126 or from the author.
}

( $\left.\mathrm{H}_{4} \mathrm{BTEC}\right)$, and so on, owing to their rational synthesis of default structures and relative high thermal stability of the obtained materials. In our understanding, the rigidity of organic linker is a double-edged sword. On one hand, it can improve thermal stability, but it also somehow limits the coordination configuration around the central metal atom for the sake of unexpected steric hindrance. Therefore new synthesis strategy should be developed to consummate it. Comparing to rigid ligands, flexible ligands are not that extensively studied in the field of metal-organic complexes, suffering to low porosity and interpenetration. Actually, they have also achieved some successes $^{[6,7]}$ and demonstrate that the flexibility of ligand plays an important role in the design and synthesis of metal-organic complexes, can be used as a complement to rigid ligands. Therefore, we decided to investigate some new multicarboxylate ligands, which combine both rigid and flexible moiety in it to explore new functional metal-organic complexes and which provide a deeper understanding of flexible ligands.

Flexible ligands can be obtained by doing some decorations to rigid ligands through the introduction of methylene, $-\mathrm{CH}_{2} \mathrm{O}-,-\mathrm{CH}_{2} \mathrm{~S}-$, or imine group into the aromatic and coordination groups. ${ }^{[7 \mathrm{c}, 8]}$ Until now, much of attention has been paid to ligands containing methylene and $-\mathrm{CH}_{2} \mathrm{O}-$ groups, ${ }^{[8 \mathrm{a}, 8 \mathrm{~b}]}$ whereas ligands decorated with imine group are less investigated. ${ }^{[7 \mathrm{c}, 8 \mathrm{c}]}$ In our opinion, this kind of ligand could be interesting because of the imine group's coordinating nature and dual role (donor and acceptor) in hydrogen interactions. Therefore, we designed and synthesized a new tritopic carboxylic acid ligand, 2,2',2', $2^{\prime \prime \prime}$-[2,3,5,6-tetramethyl-1,4phenylenebis(methylenenitrilo)]tetraacetic acid $\left(\mathrm{H}_{4} \mathrm{~L}\right)$, from 1,4-bis(bromomethyl)-2,3,5,6-tetramethylbenzene and diethyl 
iminodiacetate. Using it as ligand, three new coordination complexes $\left[\mathrm{CuL}_{0.5}\right]$ (1), $\left[\mathrm{Co}\left(\mathrm{H}_{2} \mathrm{~L}\right)\left(\mathrm{H}_{2} \mathrm{O}\right)_{2}\right]\left[\mathrm{H}_{2} \mathrm{O}\right]$ (2), and $\left[(\mathrm{CdCl})_{0.5} \mathrm{Cd}_{0.25}\left(\mathrm{H}_{2} \mathrm{~L}\right)_{0.5}\right](\mathbf{3})$ were successfully obtained under hydrothermal conditions. All the compounds were characterized by general methods including elemental analysis, $\mathrm{X}$-ray crystallography, IR, and thermogravimetric analysis.

\section{Results and Discussion}

\section{Synthetic Analysis}

Complexes 1-3 were successfully synthesized by reacting $\mathrm{H}_{4} \mathrm{~L}$ with the corresponding salts at 140 or $120^{\circ} \mathrm{C}$ for $3 \mathrm{~d}$ under hydrothermal conditions. The reaction route of $\mathbf{1 - 3}$ is shown in Scheme 1. The conditions of the respective reactions were affected by $\mathrm{pH}$ value, reaction temperature, type of salts, and metal-ligand ratio. Complex $\mathbf{1}$ is a novel 3D framework, whose optimal conditions are $140{ }^{\circ} \mathrm{C}, \mathrm{pH}$ value of 6.0 , and $\mathrm{CuSO}_{4} \cdot 5 \mathrm{H}_{2} \mathrm{O}: \mathrm{H}_{4} \mathrm{~L}$ ratio as $2: 1$. Complexes 2 and $\mathbf{3}$ were synthesized at $120{ }^{\circ} \mathrm{C}$ with different $\mathrm{pH}$ values and $M$ :ligand ratios. Different to $-\mathrm{CH}_{2}-,-\mathrm{CH}_{2} \mathrm{O}-$ and $-\mathrm{CH}_{2} \mathrm{~S}-$, imine group can not only improve the flexibility of the ligand but also involve in the coordination with central metal atoms leading to new structures.

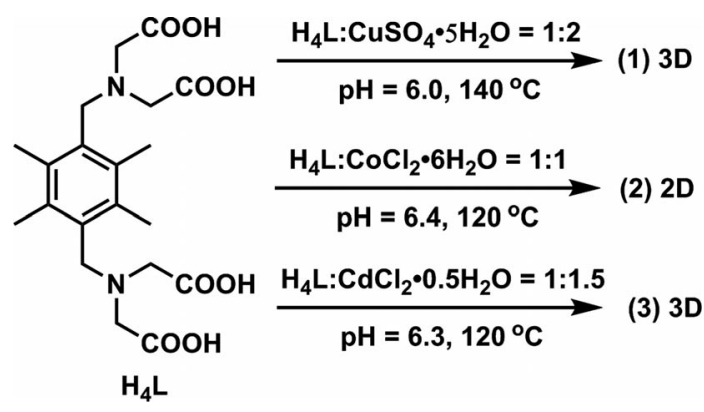

Scheme 1. Reaction routes of complexes 1-3.

\section{Description of the Structures}

The coordination modes of $\mathrm{H}_{4} \mathrm{~L}$ ligand are shown in Scheme 2. The following structure discussion is based on CIF files of complexes 1-3 and the final formulas of complexes 1-3 are further determined by elemental analyses and thermogravimetric studies.

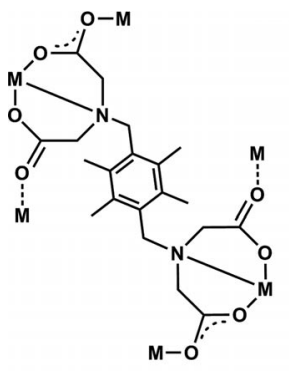

(a)

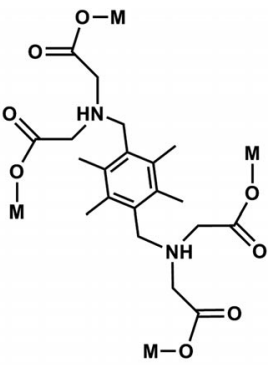

(b)

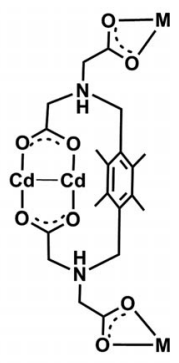

(c)
Scheme 2. Coordination modes of $\mathrm{H}_{4} \mathrm{~L}$ ligand in complexes 1-3.

\section{Description of $\left[\mathrm{CuL}_{0.5}\right](\mathbf{1})$}

X-ray crystallographic analysis revealed that complex $\mathbf{1}$ crystallizes in the orthorhombic space group $\mathrm{Pbca}$. The asymmetric unit contains one coordinated $\mathrm{Cu}^{\mathrm{II}}$ atom and half $\mathrm{L}^{4-}$ ligand (Figure 1). All carboxyl groups of $\mathrm{H}_{4} \mathrm{~L}$ are deprotonated, in agreement with the IR data, in which no characteristic absorption bands of the $-\mathrm{COOH}$ group at $1700-1750 \mathrm{~cm}^{-1}$ are observed. The central $\mathrm{Cu}^{\mathrm{II}}$ atom is five-coordinate and takes a distorted square pyramid arrangement. Each $\mathrm{Cu}^{\mathrm{II}}$ atom is chelated by a $\mathrm{L}^{4-}$ ligand via its iminonitrogen (N1) and two oxygen atoms (O1 and $\mathrm{O} 3)$ from the two iminocarboxylate arms, respectively. The remaining two face-related coordination sites are occupied by $\mathrm{O} 2 \mathrm{~B}$ and $\mathrm{O} 4 \mathrm{~F}(\mathrm{~B}: 2.5-x ; 0.5+y ;+z ; \mathrm{F}: 0.5+x$, $y, 0.5-z)$ from another two $\mathrm{L}^{4-}$ ligands. These four $\mathrm{Cu} 1-\mathrm{O}$ bonds around $\mathrm{Cu}^{2+}$ in complex $\mathbf{1}$ fall into two categories with bond lengths of $\mathrm{Cu} 1-\mathrm{O} 1$ 1.926(5), Cu1-O2B 1.941(5), Cu1O3 1.957(5), and Cu1-O4F $2.452 \AA$, respectively. The three short Cu1-O bonds distances [1.926(5)-1.957(5) $\AA$ ] are in the normal range compared to the other similar $\mathrm{Cu}-\mathrm{O}$ bonds in reported complexes. ${ }^{[9]}$ The $\mathrm{Cu} 1$ atom locates in the center of square-planar environment, which consists of three oxygen $(\mathrm{O} 1, \mathrm{O} 2 \mathrm{~B}, \mathrm{O} 3)$ atoms and one nitrogen $(\mathrm{N} 1)$ atom (Figure 2a). The longer $\mathrm{Cu}-\mathrm{O}$ bond [Cu1-O4F $2.45 \AA$ ] on the axial site, which completes the square pyramid arrangement around $\mathrm{Cu} 1$ in $\mathbf{1}$, originates from the carboxylate group of the adjacent $\mathrm{Cu}(\mathrm{L})_{0.5}$ units. Thus, each iminodiacetate group of $\mathrm{L}^{4-}$ ligand functions as a chelating tridentate ligand to the first $\mathrm{Cu}^{2+}$ and as a monodentate bridging mode to another $\mathrm{Cu}^{2+}$ (Type A, Scheme 2), which, in turn, is responsible for the formation of building blocks (Figure 2a). These building blocks are further connected to form a 2D layer in $b c$ plane (Figure 2b) through the aryl moieties of $\mathrm{L}^{4-}$. Finally, such 2D layers are connected by weak $\mathrm{Cu}-\mathrm{O}$ interactions to form a 3D architecture (Figure $2 \mathrm{c}$ ).

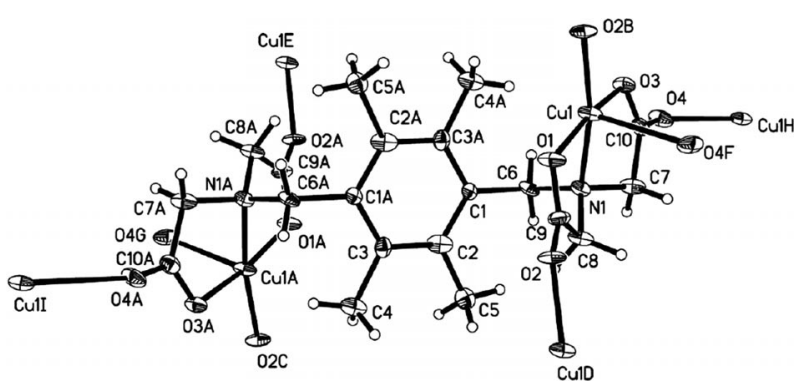

Figure 1. The coordination environment of $\mathrm{Cu}^{\mathrm{II}}$ ion in $\mathbf{1}$ with the thermal ellipsoid at the $50 \%$ probability level. Symmetry codes: (a) $2-x$, $1-y, 1-z$; (b) $2.5-x ; 0.5+y$; $+z$; (c) $-0.5+x, 0.5-y, 1-z$; (d) $2.5-x,-0.5+y$, $+z$; (e) $-0.5+x, 1.5-y, 1-z$, (f) $0.5+x, y, 0.5-z$; (g) $1.5-x, 1-y, 0.5+z$; (h) $-0.5+x, y, 0.5-z$; (i) $2.5-x, 1-y, 0.5+z$.

\section{Description of $\left[\mathrm{Co}\left(\mathrm{H}_{2} \mathrm{~L}\right)\left(\mathrm{H}_{2} \mathrm{O}\right)_{2}\right]\left[\mathrm{H}_{2} \mathrm{O}\right]$ (2)}

Complex 2 crystallizes in the monoclinic P2(1) space group. The asymmetric unit is composed of one independent central $\mathrm{Co}^{\mathrm{II}}$ atom, one partly deprotonated $\mathrm{H}_{2} \mathrm{~L}^{2-}$ ligand, two aqua ligands, and one free water molecule in a crystal lattice (Fig- 
(A)

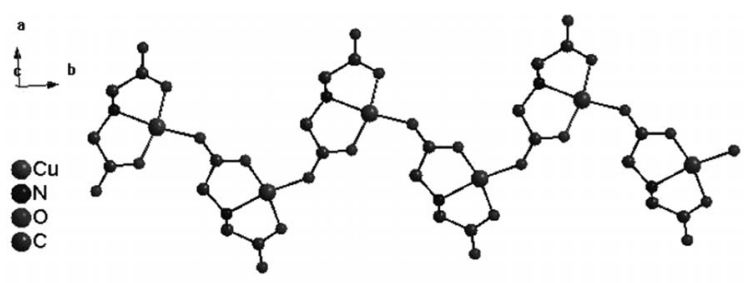

(B)

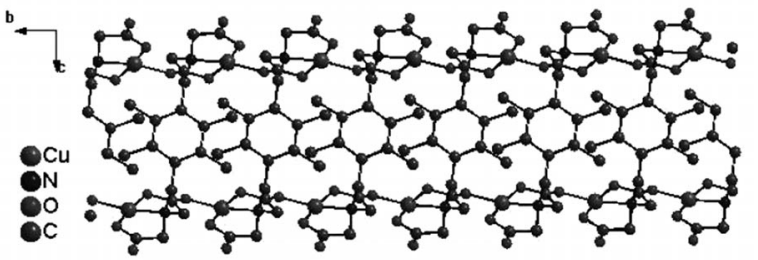

(C)

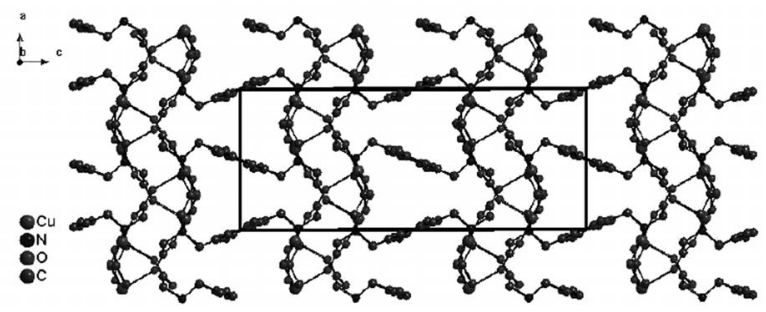

Figure 2. View of 1D chain (a) 2D layer (b) and 3D architecture (c).

ure 3). The $\mathrm{Co}^{\text {II }}$ ion has a slightly distorted octahedral arrangement with four carboxyl oxygen atoms [O4, O5A, O2C, O7B] from four different $\mathrm{H}_{2} \mathrm{~L}^{2-}$ ligands, and two aqua ligands [O1W, $\mathrm{O} 2 \mathrm{~W}]$. The $\mathrm{Co}-\mathrm{O}$ bond lengths are in the range of 2.047(4)$2.146(4) \AA$ and the O-Co-O bond angles vary from $84.13(16)$ to $176.06(15)^{\circ}$. The four carboxylic groups of the ligand are fully deprotonated with two protons transferred to the two nitrogen ( $\mathrm{N} 1$ and $\mathrm{N} 2)$ atoms, which is confirmed by crystallographic analysis as well as the IR spectroscopic data since a strong band at $3034 \mathrm{~cm}^{-1}$ was observed in the IR spectrum of 2. ${ }^{[10]}$

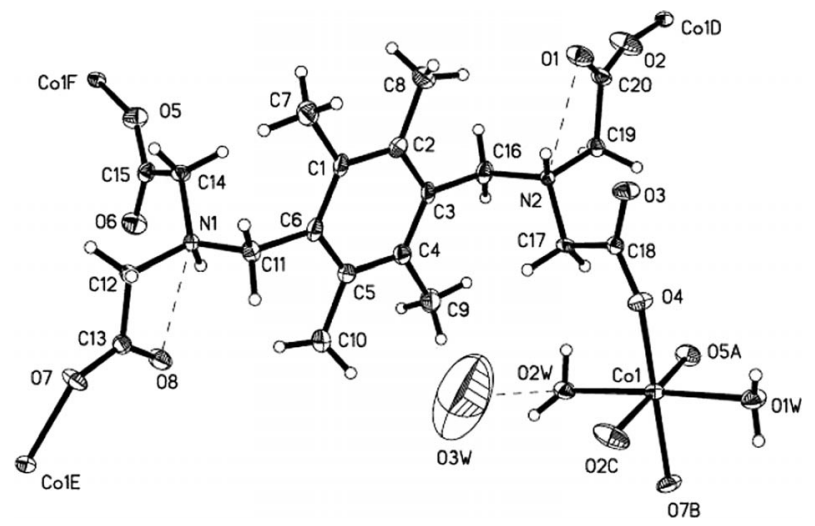

Figure 3. The coordination environment of $\mathrm{Co}^{\mathrm{II}}$ ion in $\mathbf{2}$ with the thermal ellipsoid at the $40 \%$ probability level. Symmetry codes: (a) $1-x$, $0.5+y,-z$; (b) $1-x, 0.5+y, 1-z$; (c) $+x,+y, 1+z$; (d) $+x,+y,-1+z$; (e) $1-x,-0.5+y, 1-z$; (f) $1-x,-0.5+y,-z$.

Each carboxylic group in $\mathrm{H}_{2} \mathrm{~L}^{2-}$ bridges one $\mathrm{Co}^{\mathrm{II}}$ ion monodentatly, the whole $\mathrm{H}_{2} \mathrm{~L}^{2-}$ ligand binds four $\mathrm{CO}^{\mathrm{II}}$ atoms and behaves as a 4-connected node. Through the linkage of $\mathrm{H}_{2} \mathrm{~L}^{2-}$, a 2D-network in $b c$ plane is formed (Figure 4a). In addition, there exist intramolecular hydrogen bonds (N2-H...O1 and $\mathrm{N} 1-\mathrm{H} \cdots \mathrm{O} 8)$ and intermolecular hydrogen bonds (O2W-H...O3W) (Table S2, Supporting Information). It is believed that the hydrogen-bonding interactions play an important role in stabilizing the 2D network (Figure $4 b$ ).

a

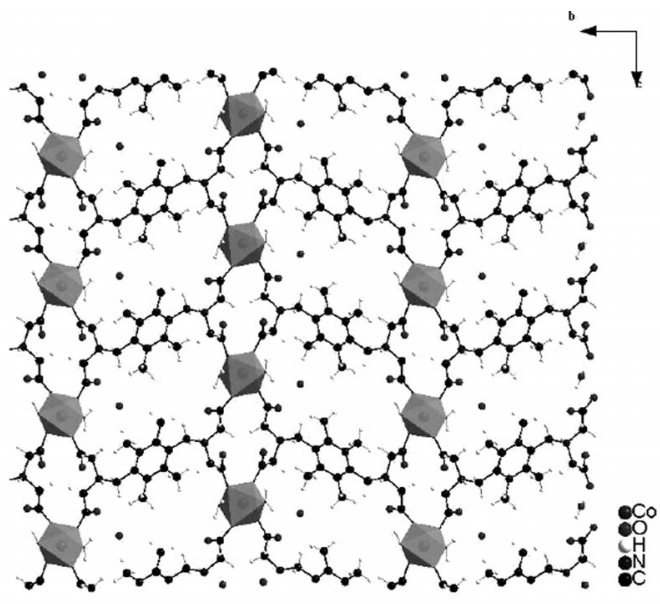

b

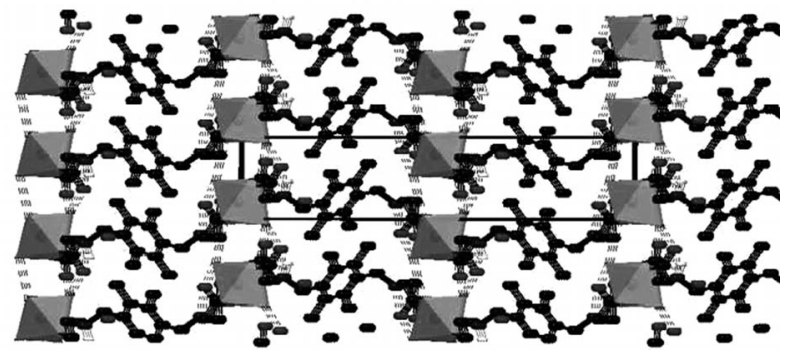

Figure 4. Two dimensional layer and pseudo three dimensional supramolecular structure of complex 2 . The $\mathrm{CoO}_{6}$ octahedra are shaded in grey. Intramolecular and intermolecular hydrogen bonds are presented as dark grey dashed lines.

\section{Description of $\left[(\mathrm{CdCl})_{0.5} \mathrm{Cd}_{0.25}\left(\mathrm{H}_{2} \mathrm{~L}\right)_{0.5}\right](\mathbf{3})$}

Complex 3 crystallizes in the tetragonal $P 4(2) / n c m$ space group and displays a three dimensional framework structure consisting of $\left[\mathrm{Cd}_{2}\left(\mathrm{CO}_{2}\right)_{4} \mathrm{Cl}_{2}\right]$ paddle wheel units and distorted $\left[\mathrm{CdO}_{8}\right]$ dodecahedra. In the asymmetrical unit, there are two crystallographic unique $\mathrm{Cd}^{2+}$ cations $(\mathrm{Cd} 1$ and $\mathrm{Cd} 2)$, half chlorine anion and half $\mathrm{H}_{2} \mathrm{~L}^{2-}$ ligand, which corresponds to the formula $\left[(\mathrm{CdCl})_{0.5} \mathrm{Cd}_{0.25}\left(\mathrm{H}_{2} \mathrm{~L}\right)_{0.5}\right]$ (see Figure 5). Two symmetry-related $\mathrm{Cd}_{1} 1^{\mathrm{II}}$ ions are bridged by four carboxylate groups of two neighboring $\mathrm{LH}_{2}{ }^{2-}$ ligands to form the paddlewheel unit $\left[\mathrm{Cd}_{2}\left(\mathrm{CO}_{2}\right)_{4} \mathrm{Cl}_{2}\right]$ with a $\mathrm{Cd}-\mathrm{Cd}$ distance of 3.2130(15) Å. Since each $\mathrm{Cd}^{2+}$ ion has square-pyramidal coordination arrangement, its axial position is occupied by a $\mathrm{Cl}^{-}$ anion with $\mathrm{Cd}-\mathrm{Cl}$ distance of 2.415(3) $\AA$ [Cl1-Cd1-O4 102.84(15) ${ }^{\circ}$; Cl1B-Cd1B-O3 102.10(15) ${ }^{\circ}$, see Table S1, Supporting Information]. The $\mathrm{Cd} 1-\mathrm{O}$ bond lengths are found in the range of 2.270(8)-2.282(5) $\AA$, and the $\mathrm{O}-\mathrm{Cd} 1-\mathrm{O}$ bond angles vary from $83.40(19)$ to $154.58(19)^{\circ}$, which are all comparable to those of other reported cadmium carboxylates. ${ }^{[11]}$ It should be noticed that this kind of dinuclear $\mathrm{Cd}^{\mathrm{II}}$ building unit is rare, only limited examples are known. ${ }^{[11]}$ Different from 
$\mathrm{Cd} 1, \mathrm{Cd} 2$ is situated at a fourfold axis and eight coordinated by eight oxygen atoms $(\mathrm{O} 1, \mathrm{O} 2$; O1E, O2E; O1F, O2F; and O1G, O2G; operators: E $0.5-x, 1.5-y,+z$; F $0.5+y, 0.5+x,-z$; G $1-y, 1-x,-z)$ of four carboxylic groups from four different $\mathrm{LH}_{2}{ }^{2-}$ ligands, forming a slight distorted $\left[\mathrm{CdO}_{8}\right]$ dodecahedron coordination sphere. The $\mathrm{Cd} 2-\mathrm{O}$ bond lengths extend from $2.369(6)$ to $2.573(6) \AA$ and the $\mathrm{O}-\mathrm{Cd} 2-\mathrm{O}$ bond angles vary from $88.2(3)$ to $176.5(3)^{\circ}$, which are all slight larger than those of Cd1 (see Table S1).

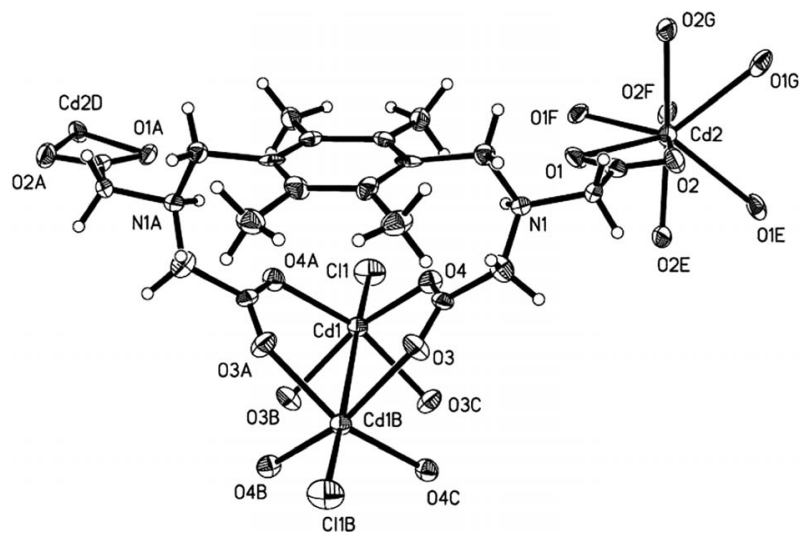

Figure 5. The coordination environment of $\mathrm{Cd}^{\mathrm{II}}$ ion in $\mathbf{3}$ with the thermal ellipsoid at the $40 \%$ probability level. Symmetry codes: (a) $1.5-y, 1.5-x,+z$; (b) $1-x, 2-y, 1-z$; (c) $-0.5+y, 0.5+x, 1-z$; (d) $1-x$, $2-y,-z$; (e) $0.5-x, 1.5-y,+z$; (f) $0.5+y, 0.5+x,-z$; (g) $1-y, 1-x,-z$.

The flexible multicarboxylate $\mathrm{H}_{2} \mathrm{~L}^{2-}$ ligand in complex 3 is fully deprotonated and two protons transferred to the two imine groups, which is confirmed by the IR spectrum. ${ }^{[12]}$ Two of the four carboxylic groups bend to the middle of the ligand and bridge two $\mathrm{Cd}^{\mathrm{II}}$ ions forming the above mentioned $\left[\mathrm{Cd}_{2}\left(\mathrm{CO}_{2}\right)_{4} \mathrm{Cl}_{2}\right]$ paddle-wheel unit, whereas another two chelate two $\mathrm{Cd} 2{ }^{\mathrm{II}}$ ions forming the distorted $\left[\mathrm{CdO}_{8}\right]$ dodecahedra (Type $\mathrm{C}$, Scheme 2). Consequently, these $\mathrm{H}_{2} \mathrm{~L}^{2-}$ ligands bridge the $\left[\mathrm{Cd}_{2}\left(\mathrm{CO}_{2}\right)_{4} \mathrm{Cl}_{2}\right]$ units and distorted $\left[\mathrm{CdO}_{8}\right]$ dodecahedra into a complicated three-dimensional compact architecture (see Figure 6).

\section{The Effect of Flexibility of the Tetracarboxylic Ligand on Crystal Structure}

Compounds 1-3 were obtained under similar reaction conditions, but display totally different structures, suggesting that their structures are mainly metal-dependent. The flexibility of the ligand allows the four carboxylic groups coordinate to different metal ions with different conformations and coordination modes. From the structure analyses it is clear that the two iminoacetic acid moieties in compounds $\mathbf{1}$ and $\mathbf{2}$ exhibit trans conformation, whereas in compound $\mathbf{3}$ cis conformation is observed. With the changing of metal ions, the coordination modes of the tatracarboxylic ligand changes also. In compound 1 the four carboxylic groups all adopt anti-anti double monodentate coordination modes. But only monodentate coordination mode is found in compound $\mathbf{2}$, and both chelating and double monodentate syn-syn bridging coordination modes are formed in compound 3 . The flexibility of the tetracarboxylic

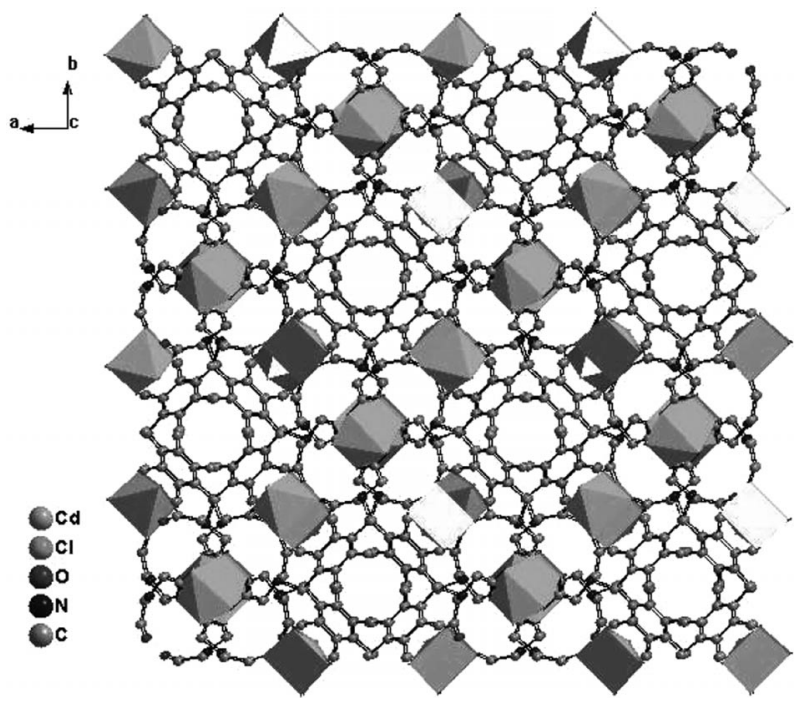

Figure 6. View of the structure of $\mathbf{3}$ down the $c$ axis. The $\left[\mathrm{Cd}(1) \mathrm{ClO}_{4}\right]_{2}$ paddle-wheel units and $\left[\mathrm{Cd}(2) \mathrm{O}_{8}\right]$ dodecahedron are shaded in grey (all hydrogen atoms are omitted for clarity).

ligand can also be intuitively embodied by the dihedral angles between the carboxylic groups and the central aromatic ring $\left(38.970,38.970,53.085,53.085^{\circ}\right.$ for $\mathbf{1}$; 13.552, 22.932, $88.097,88.830^{\circ}$ for $2 ; 18.251,18.251,48.440,48.440^{\circ}$ for 3 ). Obviously, the employment of flexible ligands can greatly enrich the structures of coordination compounds.

\section{IR, Powder XRD Analysis, and Photoluminescence Property}

The measurements of IR spectra of $\mathbf{1}, \mathbf{2}$, and $\mathbf{3}$ confirm the presence of the organic ligands used in the syntheses through the characteristic bands of aromatic and carboxylate groups (see Figure S2, Supporting Information). The broad absorption bands of the asymmetric and symmetric stretching vibrations of water appear at $3700-2700 \mathrm{~cm}^{-1}$. ${ }^{[13]}$ The bands at $1676-$ $1560 \mathrm{~cm}^{-1}$ and $1408-1334 \mathrm{~cm}^{-1}$ correspond to the asymmetric and symmetric stretching vibrations of the bound carboxylate groups $\left(-\mathrm{CO}_{2} M\right)$, respectively. In the high-frequency region, the sharp bands are observed in the $3034 \mathrm{~cm}^{-1}$ and $3157 \mathrm{~cm}^{-1}$ range for complexes 2 and $\mathbf{3}$ due to $v(\mathrm{~N}-\mathrm{H})$ vibration of the ligand. ${ }^{[9]}$ Figures S3-S5 (Supporting Information) show the powder XRD patterns of the title compounds. The experimental XRD pattern for each compound is in accordance with the simulated one generated on the basis of structural data, confirming that the as-synthesized products are pure phase. The solid state emission spectra of compound $\mathbf{3}$ and ligand $\mathrm{H}_{4} \mathrm{~L}$ were measured at room temperature. Under excitation of $250 \mathrm{~nm}$, both compound 3 and ligand $\mathrm{H}_{4} \mathrm{~L}$ show a broad featureless band with a maximum of about $396 \mathrm{~nm}$ (Figure 7), suggesting the emission of $\mathbf{3}$ might be assigned to the intraligand fluorescent emission. Comparing with the free $\mathrm{H}_{4} \mathrm{~L}$ ligand, the enhancement of luminescence of compound $\mathbf{3}$ might be attributed to ligand chelation to the central metal atom, which effectively increases the rigidity of the ligand and reduces the loss of energy by radiationless decay. ${ }^{[13]}$ 


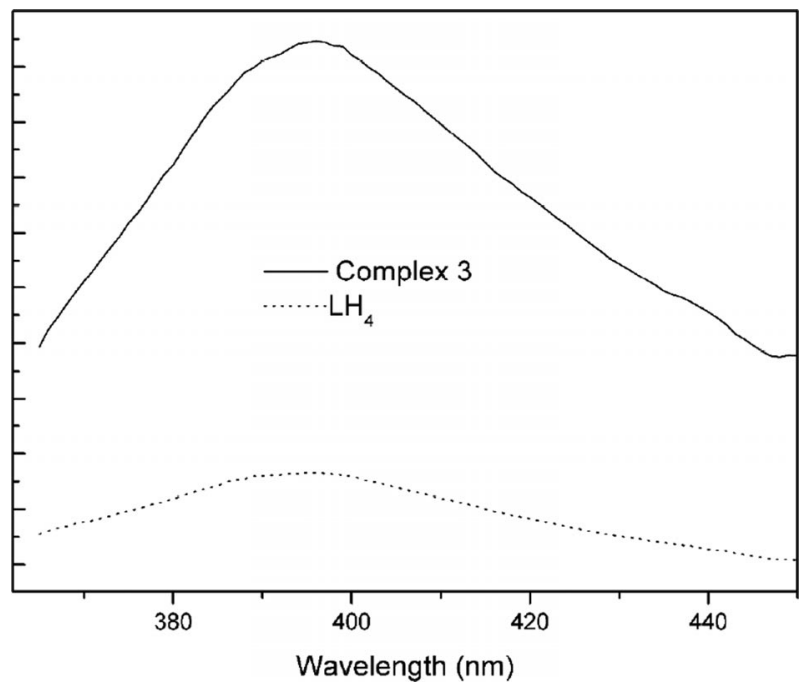

Figure 7. The emission spectra in the solid state at room temperature: free $\mathrm{H}_{4} \mathrm{~L}$ ligand $\left(\lambda_{\mathrm{ex}}=250 \mathrm{~nm}\right.$, dot line); complex $3\left(\lambda_{\mathrm{ex}}=250 \mathrm{~nm}\right.$, solid line).

\section{Thermal Stabilities of Complexes 1-3}

Thermogravimetric analyses (TGA) were carried out in a nitrogen atmosphere to examine the thermal stability of complexes 1-3 and the results are shown in Figure 8. Complex $\mathbf{1}$ is stable up to about $240{ }^{\circ} \mathrm{C}$, and decomposes rapidly on further heating. For complex 2, the weight loss in the range of 50$225^{\circ} \mathrm{C}$ corresponds to the departure of one lattice water molecule and two coordinated aqua molecules (calcd. 10.10\%, found $9.75 \%$ ), and the framework undergoes decomposition in the range of $225-420{ }^{\circ} \mathrm{C}$. There is no obvious weight loss before $310^{\circ} \mathrm{C}$ for complex $\mathbf{3}$, indicating no solvent molecules accommodated in the structure and good stability. Finally, it decomposes rapidly till $600{ }^{\circ} \mathrm{C}$.

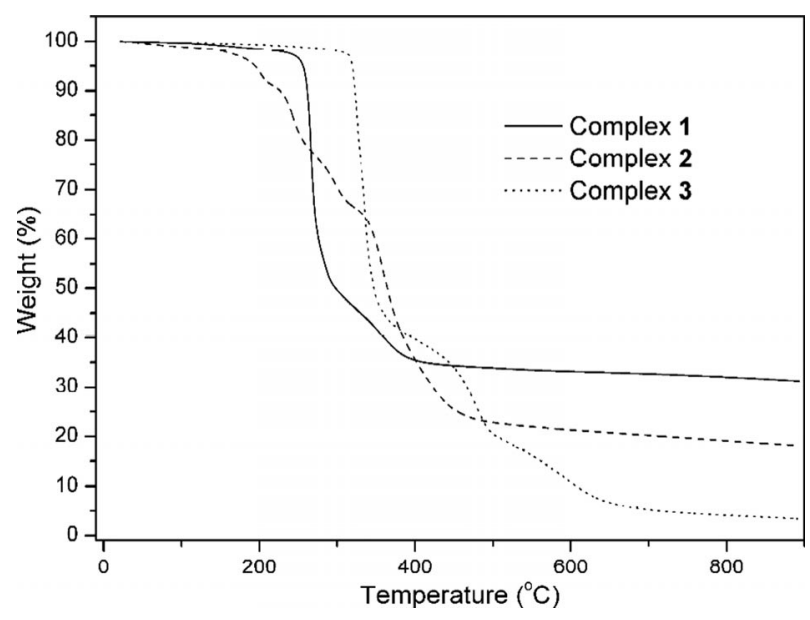

Figure 8. Thermal gravimetric curves of complexes 1-3.

\section{Conclusions}

Three new metal-organic coordination polymers based on flexible multicarboxylate ligand were synthesized and thor- oughly characterized using IR, EA, powder and single-crystal $\mathrm{X}$-ray diffraction, TGA, and luminescence measurements. The structure measurements indicate that the multicarboxylate ligand in complexes 1-3 shows varied coordination modes to different transition metals and results in three different types of structures. The imine groups exhibit affinity to copper ions since only in the copper compound they are involved in the coordination, whereas central $\mathrm{Cd}^{\mathrm{II}}$ atoms are more propitious to form paddle-wheel units under synthesis conditions used in this research. The structure results also indicated that the introduction of imine groups and methyl groups to multicarboxylate ligand is a promising strategy to fabricate new MOFs with a specific structure.

\section{Experimental Section}

General: All solvents and reagents for the syntheses were of analytical grade and were used as received from commercial sources without further purification. 1,4-Bis(bromomethyl)-2,3,5,6-tetramethylbenzene was prepared as described in the literature. ${ }^{[14]}$ Diethyl iminodiacetate was purchased from Aldrich. Elemental analyses for $\mathrm{C}, \mathrm{H}$, and $\mathrm{N}$ were carried out with a German Elementary Vario EL cube instrument. The IR spectra were performed with a Nicolet 6700 FTIR spectrometer in the region $4000-400 \mathrm{~cm}^{-1}$ using $\mathrm{KBr}$ pellets. Thermogravimetric analyses were recorded with a NETZSCH STA 449C unit at a heating rate of $10{ }^{\circ} \mathrm{C} \cdot \mathrm{min}^{-1}$ in a nitrogen atmosphere. The powder X-ray diffraction (XRD) patterns were collected with a D8 Advance X-ray diffractometer using $\mathrm{Cu}-K_{\alpha}$ radiation $(\lambda=0.154 \mathrm{~nm})$. Fluorescent analysis of the complexes was performed with a Fluoromax-4. In the measurements of emission and excitation spectra the pass width is $5 \mathrm{~nm}$, and all the measurements were carried out under the same experimental conditions.

Synthesis of $\mathbf{H}_{\mathbf{4}} \mathbf{L}: 2,2^{\prime}, 2^{\prime \prime}, 2^{\prime \prime \prime}{ }^{\prime \prime}$ [2,3,5,6-Tetramethyl-1,4-phenylenebis(methylenenitrilo)]tetraacetic acid $\left(\mathrm{H}_{4} \mathrm{~L}\right)$ (see Scheme S1, Supporting Information) was synthesized according to the literature. ${ }^{[7]}{ }^{\mathbf{1}} \mathbf{H}$ NMR $\left(600 \mathrm{MHz},\left[\mathrm{D}_{6}\right] \mathrm{DMSO}, \mathrm{ppm}\right)$ (see Figure S1): $\delta=12.30$ (s, 4 $\mathrm{H},-\mathrm{COOH}), 3.92\left(\mathrm{~s}, 4 \mathrm{H}, \mathrm{Ar}-\mathrm{CH}_{2}\right) ; 3.37\left(\mathrm{~s}, 8 \mathrm{H}, \mathrm{N}-\mathrm{CH}_{2}-\mathrm{COOH}\right)$; 2.22 (s, $\left.12 \mathrm{H}, \mathrm{Ar}-\mathrm{CH}_{3}\right)$ ppm. $\mathrm{C}_{20} \mathrm{H}_{28} \mathrm{~N}_{2} \mathrm{O}_{8}$ : calcd. C 56.59; H 6.65; N $6.60 \%$; found: C 56.41; H 6.78; N 6.30\%. IR (KBr, selected data): $\tilde{v}=3431$ (br), 1686 (s), 1540 (vs), 1461 (w), 1424 (s), 1369 (vs), 1316 (vs), 1256 (w), 1190 (w), 1003 (vs), 955 (vs), 843 (vs), 793 (vs), 698 (vs) $\mathrm{cm}^{-1}$ (see Figure S2).

Synthesis of $\left[\mathrm{CuL}_{\mathbf{0 . 5}}\right]$ (1): A mixture of $\mathrm{H}_{4} \mathrm{~L}(0.17 \mathrm{~g}, 0.4 \mathrm{mmol})$ and $\mathrm{CuSO}_{4} \cdot 5 \mathrm{H}_{2} \mathrm{O}(0.20 \mathrm{~g}, 0.8 \mathrm{mmol})$ was dissolved in distilled water $(15 \mathrm{~mL})$ and stirred for $15 \mathrm{~min}$. The $\mathrm{pH}$ value of the obtained mixture was adjusted to ca. 6.0 with $\mathrm{NaOH}$. Afterwards, the solution was transferred into a $25 \mathrm{~mL}$ Teflon-lined container. The container containing the above solution was placed in an autoclave and heated at $140{ }^{\circ} \mathrm{C}$ for $3 \mathrm{~d}$. The autoclave was allowed to cool to $30^{\circ} \mathrm{C}$ in $24 \mathrm{~h}$. Blue block crystals of complex 1 were collected in $58 \%$ yield based on

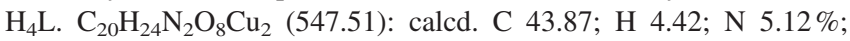
found: C 43.25; H 4.09; N 5.03\%. IR (KBr, selected data): $\tilde{v}=3431$ (br), 1627 (s), 1560 (s), 1404 (vs), 1334 (w), 1309 (w), 1117 (w), 999 (w), 887 (vs), 748 (vs) $\mathrm{cm}^{-1}$ (see Figure S2).

Synthesis of $\left[\mathrm{Co}\left(\mathrm{H}_{2} \mathrm{~L}\right)\left(\mathrm{H}_{2} \mathrm{O}\right)_{2}\right]\left[\mathrm{H}_{2} \mathrm{O}\right]$ (2): Complex 2 was synthesized in an analogous procedure to $\mathbf{1}$ except that $0.095 \mathrm{~g}(0.4 \mathrm{mmol})$ $\mathrm{CoCl}_{2} \cdot 6 \mathrm{H}_{2} \mathrm{O}$ was used instead of $\mathrm{CuSO}_{4} \cdot 5 \mathrm{H}_{2} \mathrm{O}$ and heated at $120{ }^{\circ} \mathrm{C}$. The reactant mixture was cooled to lead to the formation of pink needle crystals of $2 . \mathrm{C}_{20} \mathrm{H}_{32} \mathrm{~N}_{2} \mathrm{O}_{8} \mathrm{Co}$ (535.41): calcd. C 44.87; $\mathrm{H} \mathrm{6.02;}$ 
Table 1. Crystal data and structure refinements for complexes 1-3.

\begin{tabular}{|c|c|c|c|}
\hline & 1 & 2 & 3 \\
\hline Formula & $\mathrm{C}_{10} \mathrm{H}_{12} \mathrm{NO}_{4} \mathrm{Cu}$ & $\mathrm{C}_{20} \mathrm{H}_{32} \mathrm{~N}_{2} \mathrm{O}_{11} \mathrm{Co}$ & $\mathrm{C}_{10} \mathrm{H}_{12} \mathrm{NO}_{4} \mathrm{Cl}_{0.5} \mathrm{Cd}_{0.75}$ \\
\hline Mol. weight /g & 273.75 & 535.41 & 313.24 \\
\hline Crystal system & orthorhombic & monoclinic & tetragonal \\
\hline Space group & Pbca & $P 2(1)$ & $P 4(2) / n c m$ \\
\hline$a / \AA$ & $9.1648(11)$ & $5.2091(12)$ & $19.0440(6)$ \\
\hline$b / \AA$ & $9.2984(11)$ & $24.732(6)$ & $19.0440(6)$ \\
\hline$c / \AA$ & $22.768(3)$ & $8.933(2)$ & $11.8804(8)$ \\
\hline$a /^{\circ}$ & 90.00 & 90.00 & 90.00 \\
\hline$\beta /^{\circ}$ & 90.00 & $99.068(3)$ & 90.00 \\
\hline$\gamma /{ }^{\circ}$ & 90.00 & 90.00 & 90.00 \\
\hline$Z$ & 8 & 2 & 16 \\
\hline$V / \AA^{3}$ & $1940.3(4)$ & $1136.5(4)$ & 4308.7(3) \\
\hline Density $/ \mathrm{g} \cdot \mathrm{cm}^{-3}$ & 1.874 & 1.559 & 1.932 \\
\hline$\mu / \mathrm{mm}^{-1}$ & 2.248 & 0.819 & 1.670 \\
\hline$F(000)$ & 1120 & 558 & 2504 \\
\hline Reflections collected/unique & 6846/1711/0.0917 & $7854 / 4507 / 0.0474$ & 20750/1982/0.1378 \\
\hline Data / restraints / parameters & $1711 / 0 / 147$ & 4507 / 7 / 312 & $1982 / 18$ / 194 \\
\hline Final $R$ indices $\left[R_{1}>2 \sigma(I)\right]$ & $R_{1}=0.0626, w R_{2}=0.1593$ & $R_{1}=0.0510, w R_{2}=0.1048$ & $R_{1}=0.0510, w R_{2}=0.1310$ \\
\hline GOF on $F^{2}$ & 1.049 & 1.019 & 1.139 \\
\hline Largest diff. peak and hole $/ \mathrm{e} \cdot \AA^{-3}$ & 0.791 and -0.726 & 0.547 and -0.444 & 0.983 and -0.774 \\
\hline
\end{tabular}

N 5.23\%; found: C 44.65; H 5.96; N 5.26\%. IR (KBr, selected data): $\tilde{\mathrm{v}}=3409$ (br), 3034 (s), 3020 (s), 2977 (vs), 1676 (vs), 1635 (s), 1408 (s), 1369 (s), 1315 (vs), 1251 (w), 1186 (w), 916 (vs), 715 (vs), 676 (vs) $\mathrm{cm}^{-1}$ (see Figure S2).

Synthesis of $\left[(\mathbf{C d C l})_{0.5} \mathbf{C d}_{0.25}\left(\mathrm{H}_{2} \mathrm{~L}\right)_{0.5}\right]$ (3): Complex 3 was prepared by a procedure similar to that used for the preparation of $\mathbf{1}$ except for using $\mathrm{CdCl}_{2} \cdot 0.5 \mathrm{H}_{2} \mathrm{O}(0.14 \mathrm{~g}, 0.6 \mathrm{mmol})$ instead of $\mathrm{CuSO}_{4} \cdot 5 \mathrm{H}_{2} \mathrm{O}$ and being synthesized at $120{ }^{\circ} \mathrm{C}$. Colorless needle crystals of complex 3 were collected in $59 \%$ yield based on $\mathrm{H}_{4} \mathrm{~L} . \mathrm{C}_{20} \mathrm{H}_{26} \mathrm{~N}_{2} \mathrm{O}_{8} \mathrm{ClCd}_{1.5}$ (626.50): calcd. C 38.34; H 4.18; N 4.47\%; found: C 38.18; H 4.02; N $4.51 \%$. IR (KBr, selected data): $\tilde{v}=3440$ (br), 3157 (w), 1657 (s), 1628 (s), 1399 (vs), 1344 (vs), 1269 (w), 913 (w), 860 (w), 723 (vs) $\mathrm{cm}^{-1}$ (see Figure S2).

X-ray Crystallography: All the structure data of complexes 1-3 were collected with a Rigaku Mercury CCD diffractometer equipped with a graphite-monochromated Mo- $K_{\alpha}$ radiation $(\lambda=0.71073 \AA)$ at room temperature. All of the structures were resolved by the direct method and refined by full-matrix least-squares fitting on $F^{2}$ by SHELX-97. ${ }^{[15]}$ All non-hydrogen atoms were refined with anisotropical thermal parameters. The hydrogen atoms of the water molecules were found in the electron density map and refined by riding except that belonging to free water molecule $(\mathrm{O} 3 \mathrm{~W})$ atom in $\mathbf{2}$, which cannot be found. The other hydrogen atoms were located at geometrically calculated positions and refined by riding. Six carbon atoms (C5, C6, C7, C8, C9, $\mathrm{C} 10)$ in complex $\mathbf{3}$ are disordered and are refined using carbon atoms split over two equivalent sites with a total occupancy of $\mathbf{1}$. Crystallographic data and structure refinement results are summarized in Table 1. Selected bond lengths and bond angles are listed in Table S1 (Supporting Information). More details on the crystallographic studies as well as atomic displacement parameters are given in Supporting Information as CIF files.

Crystallographic data (excluding structure factors) for the structures in this paper have been deposited with the Cambridge Crystallographic Data Centre, CCDC, 12 Union Road, Cambridge CB21EZ, UK. Copies of the data can be obtained free of charge on quoting the depository numbers CCDC-871654 (1), CCDC-871653 (2), and CCDC-871652 (3) (Fax: +44-1223-336-033; E-Mail: deposit@ccdc.cam.ac.uk, http://www.ccdc.cam.ac.uk).
Supporting Information (see footnote on the first page of this article): Results of the TG/DTA measurements, Raman- and UV/Vis spectra, XRPD patterns, results of the Rietveld refinements as well as the ORTEP presentations.

\section{Acknowledgements}

We thank the National Natural Science Foundation of China (21073216, 21171173 and 21173246) and the "Hundred-talent Project" (KJCX2-YW-W34) of the Chinese Academy of Sciences for the financial support. We also acknowledge Mr. Anthony S. Hall for the help with editing English.

\section{References}

[1] a) M. Eddaoudi, D. B. Moler, H. L. Li, B. L. Chen, T. M. Reineke, M. O' Keeffe, O. M. Yaghi, Acc. Chem. Res. 2001, 34, 319-330; b) O. R. Evans, W. Lin, Acc. Chem. Res. 2002, 35, 511-522; c) S. L. James, Chem. Soc. Rev. 2003, 32, 276-288; d) L. Ma, C. Abney, W. Lin, Chem. Soc. Rev. 2009, 38, 1248-1256; e) M. Kurmoo, Chem. Soc. Rev. 2009, 38, 1353-1379; f) J. J. Perry IV, J. A. Perman, M. J. Zaworotko, Chem. Soc. Rev. 2009, 38, 1400-1417; g) J.-R. Li, R. J. Kuppler, H.-C. Zhou, Chem. Soc. Rev. 2009, 38, 1477-1504; h) D. Farrusseng, S. Aguado, C. Pinel, Angew. Chem. Int. Ed. 2009, 48, 7502-7513.

[2] a) M. Ruben, J. Rojo, F. J. Romero-Salguero, L. H. Uppadine, J.M. Lehn, Angew. Chem. Int. Ed. 2004, 43, 3644-3662; b) M.-H. Zeng, W.-X. Zhang, X.-Z. Sun, X.-M. Chen, Angew. Chem. Int. Ed. 2005, 44, 3079-3082; c) Y.-F. Zhou, M.-C. Hong, X.-T. Wu, Chem. Commun. 2006, 135-143; d) M. Du, X.-J. Jiang, X.-J. Zhao, H. Cai, J. Ribas, Eur. J. Inorg. Chem. 2006, 1245-1254; e) K. Oisaki, Q. Li, H. Furukawa, A. U. Czaja, O. M. Yaghi, J. Am. Chem. Soc. 2010, 132, 9262-9264; f) R. Thakuria, B. Sarma, A. Nangia, New J. Chem. 2010, 34, 623-636.

[3] a) J. Zhang, Y. G. Yao, X. H. Bu, Chem. Mater. 2007, 19, 5083 5089; b) L. F. Ma, L. Y. Wang, X. K. Huo, Y. Y. Wang, Y. T. Fan, J. G. Wang, S. H. Chen, Cryst. Growth Des. 2008, 8, 620-628; c) S. L. Li, Y. Q. Lan, J. S. Qin, J. F. Ma, J. Liu, J. Yang, Cryst. Growth Des. 2009, 9, 4142-4146; d) Q. Gao, F. L. Jiang, M. Y. Wu, Y. G. Huang, W. Wei, M. C. Hong, Cryst. Growth Des. 2010, 10, 184-190; e) S. R. Batten, J. Solid State Chem. 2005, 178, 2475-2579. 
[4] a) G. Férey, C. Mellot-Draznieks, C. Serre, F. Millange, Acc. Chem. Res. 2005, 38, 217-225; b) M. L. Tong, S. Kitagawa, H. C. Chang, M. Ohba, Chem. Commun. 2004, 418-419; c) F. Y. Lian, F. L. Jiang, D. Q. Yuan, J. T. Chen, M. Y. Wu, M. C. Hong, CrystEngComm 2008, 10, 905-914.

[5] a) S. R. Batten, CrystEngComm 2001, 18, 1-7; b) N. W. Ockwig, O. Delgado-Friedrichs, M. O'Keeffe, O. M. Yaghi, Acc. Chem. Res. 2005, 38, 176-182; c) C. N. R. Rao, S. Natarajan, R. Vaidhyanathan, Angew. Chem. Int. Ed. 2004, 43, 1466-1496; d) S. Kitagawa, R. Kitaura, S.-I. Noro, Angew. Chem. Int. Ed. 2004, 43, 2334-2375; e) M. Du, X. J. Jiang, X. J. Zhao, Inorg. Chem. 2006, 45, 3998-4006; f) F. A. A. Paz, J. Klinowski, Inorg. Chem. 2004, 43, 3882-3893; g) H. Abourahma, B. Moulton, V. Kravtsov, M. J. Zaworotko, J. Am. Chem. Soc. 2002, 124, 9990-9991; h) R. Wang, M. Hong, J. Luo, R. Cao, Q. Shi, J. Weng, Eur. J. Inorg. Chem. 2002, 2904-2912.

[6] a) G. L. Zhuang, X. J. Sun, L. S. Long, R. B. Huang, L. S. Zheng, Dalton Trans. 2009, 38, 4640-4642; b) Q. D. Liu, J. R. Li, S. Gao, B. Q. Ma, H. Z. Kou, L. Ouyang, R. L. Huang, X. X. Zhang, K. B. Yu, Chem. Eur. J. 2003, 9, 731-736; c) B. Zhai, L. Yi, H. S. Wang, B. Zhao, P. Cheng, D. Z. Liao, S. P. Yan, Inorg. Chem. 2006, 45, 8471-8473; d) H. B. Cui, B. Zhou, L. S. Long, Y. Okano, H. Kobayashi, A. Kobayashi, Angew. Chem. Int. Ed. 2008, 47, 3376-3380.

[7] a) J. X. Ma, X. Q. Song, W. Dou, X. F. Huang, W. S. Liu, Synth. React. Inorg. Met.-Org. Nano-Met. Chem. 2008, 38, 721-726; b) J. Ma, F. L. Jiang, L. Chen, M. Y. Wu, S. Q. Zhang, D. Han, R. Feng, M. C. Hong, Cryst. Growth Des. 2011, 11, 3273-3281; c) Y. Q. Xu, D. Q. Yuan, B. L. Wu, L. Han, M. Y. Wu, F. L. Jiang, M. C. Hong, Cryst. Growth Des. 2006, 6, 1168-1174; d) C. Drouza, A. D. Keramidas, Inorg. Chem. 2008, 47, 7211-7224; e) L. S. Natrajan, P. L. Timmins, M. Lunn, S. L. Heath, Inorg. Chem. 2007, 46, 10877-10886; f) M. L. Liu, W. Shi, H. B. Song, P. Cheng, D. Z. Liao, S. P. Yan, CrystEngComm 2009, 11, 102-108; g) D. P. Walsh, R. Clérac, N. G. Hearns, P. E. Kruger, W. Schmitt, CrystEngComm 2009, 11, 1666-1673.

[8] a) H. F. Zhu, W. Y. Sun, T. A. Okamura, N. Ueyame, Inorg. Chem. Commun. 2003, 6, 168-173; b) Z. R. Pan, H. G. Zheng, T. W. Wang, Y. Song, Y. Z. Li, Z. J. Guo, S. R. Batten, Inorg. Chem. 2008, 47, 9528-9536; c) Y. M. Zhao, S. R. Zhu, M. Shao,
X. He, M. X. Li, W. C. Lu, Inorg. Chem. Commun. 2008, 11, 239242.

[9] a) S. L. Laborda, R. Clerac, C. E. Anson, A. K. Powell, Inorg. Chem. 2004, 43, 5931-5943; b) Y. M. Zhao, S. R. Zhu, M. Shao, T. T. Jia, M. X. Li, W. C. Lu, W. J. He, Inorg. Chem. Commun. 2008, 11, 925-928; c) J. Fielden, K. Quasdorf, A. Ellern, P. Kögerler, Eur. J. Inorg. Chem. 2009, 717-720.

[10] a) S. Mukhopadhyay, P. B. Chatterjee, D. Mandal, G. Mostafa, A. Caneschi, J. Van Slageren, T. J. R. Weakley, M. Chaudhury, Inorg. Chem. 2004, 43, 3413-3420; b) J. A. Gould, J. Bacsa, H. Park, J. B. Claridge, A. M. Mogg, V. Ramanathan, J. E. Warren, M. J. Rosseinsky, Cryst. Growth Des. 2010, 10, 2977-2982.

[11] a) T. Allman, R. C. Goel, N. K. Jha, A. L. Beauchamp, Inorg. Chem. 1984, 23, 914-918; b) S.-L. Li, T. C. W. Mak, J. Chem. Soc. Dalton Trans. 1995, 1519-1524; c) J. P. Li, L. K. Li, H. W. Hou, Y. T. Fan, L. H. Gao, Inorg. Chim. Acta 2009, 362, 46714677; d) A. D. Burrows, C. G. Frost, M. Kandiah, L. L. Keenan, M. F. Mahon, T. L. Savarese, J. E. Warren, Inorg. Chim. Acta 2011, 366, 303-309.

[12] a) O. M. Yaghi, H. L. Li, T. L. Groy, J. Am. Chem. Soc. 1996, 118, 9096-9101; b) R. Lyszczek, J. Therm. Anal. Calorim. 2008, 91, 595-599; c) Z. H. Sun, W. T. Yu, X. F. Cheng, X. Q. Wang, G. H. Zhang, G. Yu, H. L. Fan, D. Xu, Opt. Mater. 2008, 30, 1001-1006; d) J. H. He, Y. T. Zhang, Q. H. Pan, J. H. Yu, H. Ding, R. R. Xu, Microporous Mesoporous Mater. 2006, 90, 145152.

[13] a) X.-R. Hao, X.-L. Wang, Z.-M. Su, K.-Z. Shao, Y.-H. Zhao, Y.Q. Lan, Y.-M. Fu, Dalton Trans. 2009, 8562-8566; b) S. L. Zheng, X. M. Chen, Aust. J. Chem. 2004, 57, 703-712; c) Photochemistry and Photophysics of Coordination Compounds (Eds.: H. Yersin, A. Vogler), Springer, Berlin, 1987; d) B. Valeur, Molecular Fluorescence: Principles and Application, Wiley-VCH, Weinheim, 2002.

[14] A. W. van der Made, R. H. van der Made, J. Org. Chem. 1993, $58,1262-1263$.

[15] G. M. Sheldrick, SHELXS-97, Programs for X-ray Crystal Structure Solution; University of Göttingen, Germany, 1997.

Received: February 28, 2013

Published Online: April 26, 2013 